\title{
Implementing Welfare-to-Work Services: A Study of Staff Decision-Making
}

\author{
Michelle A. Johnson, Julian Chun-Chung Chow, Virginia Ketch, \& \\ Michael J. Austin
}

\begin{abstract}
In the post-welfare reform era, increased discretion has been given to frontline staff for day-today welfare policy implementation. To determine how frontline staff address the complex needs of welfare program participants in this new policy environment, the decision-making processes of welfare staff $(\mathrm{N}=52)$ in 11 San Francisco Bay Area county social service agencies were assessed through a case vignette using a Web-based survey design. We examined staff decision making in four areas: problem recognition, goal formulation, information search processes, and evaluation. The results suggest that the high level of staff discretion apparent in the day-to-day implementation of welfare policy may have important implications for participants. Several recommendations for policy, practice, and future research are presented.
\end{abstract}

$\mathbf{T}$ he passage of the Personal Responsibility and Work Opportunity Reconciliation Act of 1996 (PRWORA) fundamentally changed the U.S. welfare system by devolving federal welfare program authority to state and local governments through the Temporary Aid to Needy Families (TANF) program. Although PRWORA still requires that eligible families include a minor child and that states meet maintenance-of-effort requirements, states have dramatically changed their policies and practices on a number of dimensions, such as the size and number of benefits, as well as the nature of work requirements, exemptions, and time limits. Lipsky's (1980) theory of street-level bureaucracy suggests that frontline staff in large public bureaucracies create policy through the use of discretion and autonomy embedded in day-to-day decision-making. In the case of devolving authority to implement welfare reform, the duties of frontline workers were expanded to include eligibility determination, assessment, case management, and service linkage. Today, frontline staff have more flexibility and discretion in their jobs than they had prior to welfare reform (Nathan \& Gais, 1999; Brodkin, 2000; Morgen, 2001; Hagen \& Owens-Manley, 2002; Lurie, 2002; Riccucci, 2002).

The legislation that created California's welfare reform program, California Work Opportunity and Responsibility to Kids (CalWORKs), limited cash assistance to a 60month period within which nonexempt CalWORKs adults are eligible to receive 18 or 24 months of welfare-to-work services with the goal of obtaining unsubsidized employment. After fulfilling the initial job search requirement, participants are required to work or participate in a workrelated activity for 32 to 35 hours per week, depending upon family structure. The CalWORKs program also gave counties the discretion to develop their own welfare-towork programs, including work-related activities, community service opportunities, and criteria for nonparticipation. Policy flexibility for the program includes the use of diversion payments and exemptions for domestic violence 
(Montgomery et al., 2002). As a result, CalWORKs staff are now responsible for implementing a complex service delivery system based on the policies set forth in each county's CalWORKs plan, approved by the state for implementation in 1998. To gain insight into how welfare reform implementation is taking shape, an exploratory study of decision making among CalWORKs staff in the San Francisco Bay Area was conducted in collaboration with participating CalWORKs agency directors affiliated with the Bay Area Social Services Consortium (BASSC; Austin et al., 2003).

\section{Background}

The research conducted prior to federal welfare reforms provides some insight into the experiences and perceptions of frontline staff during a time of changing welfare policy. In their studies of the Job Opportunities and Basic Skills Training (JOBS) program, Jan Hagen and her colleagues found that workers, in general, supported the JOBS goal of promoting participant self-sufficiency (Hagen, Lurie, \& Wang, 1993; Hagen \& Lurie, 1995a). However, only half of the workers felt the program was helpful to participants due to barriers to program implementation, such as inadequate funding for education and training services and lack of employment opportunities in the community. Frontline welfare staff generally felt that their agencies emphasized the opportunities available to participants in the JOBS program rather than their obligation to participate in the program (Hagen et al., 1993; Hagen \& Wang, 1993; Hagen \& Lurie, 1995a; Hagen \& Lurie, 1995b). This was consistent with staff beliefs that it was more important to emphasize opportunities and improve participants' skills than to focus on program requirements.

In a study conducted after welfare reform, Hagen and Owens-Manley (2002) found that frontline workers generally expressed agreement with the new emphasis in the TANF program on employment and acknowledged a clear philosophical shift from granting money to requiring work; however, they questioned TANF's effectiveness for long-term welfare recipients and those needing additional assistance to achieve economic self-sufficiency. Gais et al. (2001), on the other hand, found that frontline staff almost always mentioned the required work activities during the initial application process with participants, reflecting the new emphasis on "WorkFirst." In contrast, Meyers et al. (2001) found that welfare staff rarely acted in ways consistent with the formal TANF policy goals of moving participants from welfare to work, specifically by failing to emphasize the importance of work or the availability of work-related services.

The shift in the organizational culture of the welfare office from eligibility determination to employmentfocused case management services required considerable job redesign for TANF staff. In many locales, employment and social service organizations have been given more shared responsibility over welfare program operations (Nathan \& Gais, 1999; Holcomb \& Martinson, 2002). Early TANF implementation research identified collaboration with other agencies and community organizations as an important element of TANF service delivery reform (Carnochan \& Austin, 2002). More recent studies have described the challenges and opportunities of collaboration between public welfare organizations and private welfareto-work contractors (Sandfort, 1999; Prince \& Austin, 2002; Austin et al., 2003; Doolittle, Gooden, \& Robles, 2003).

The flexibility and discretion that has been granted through the implementation of welfare reform has allowed staff in local offices to influence participants' access to services and to define the terms of participant success (Brodkin, 2000; Morgen, 2001; Cherlin, Bogen, Quane, \& Burton, 2002; Hagen \& Owens-Manley, 2002; Riccucci, 2002; Doolittle, Gooden, \& Robles, 2003; Hasenfeld, Ghose, \& Larson, 2004; Keiser, Mueser, \& Choi, 2004). For example, Hagen and Owens-Manley (2002), in a study of decision making among frontline staff regarding the domestic violence exemption, found that most staff placed primary emphasis on the participant's efforts to help herself and gave lower priority to participants who repeatedly returned to a violent partner and were more dependent on welfare. Hasenfeld et al.'s (2004) and Keiser et al.'s (2004) findings that participants of color were more likely to be sanctioned by frontline staff when compared to White participants suggests two possibilities. Minorities may have characteristics that make them more susceptible to sanctions or biased racial attitudes may play a role in welfare staff decisions.

The level of discretion accorded to frontline CalWORKs staff is reflected in the design of CalWORKs programs. To illustrate, when a participant first enters the system, the staff member must decide whether to offer participants a diversion package, cash aid, or a service plan. A service plan can help the participant enter into a job search, receive an assessment, develop an employment plan, or receive other needed services (e.g., education, training, English language development, or mental health services). Frontline staff are also responsible for providing case management and post-employment services after aid has been reduced or terminated.

\section{Methods}

\section{Study Design}

To gain an understanding of how CalWORKs staff assess complex cases, study participants were invited to respond to a series of questions that related to a hypothetical case vignette, which was administered through a Web-based survey. Case vignettes have been used to assess decision making across a range of clinical and professional settings, including welfare programs (Hagen \& Owens-Manley, 
TABLE 1. Decision-Making Framework and Study Questions Regarding the Case Vignette

\begin{tabular}{|c|c|}
\hline DECISION STAGE & DESCRIPTION \\
\hline \multicolumn{2}{|l|}{ Stage 1} \\
\hline Recognition & $\begin{array}{l}\text { A problem or situation is recognized as one that requires a } \\
\text { decision. During this stage, "predecisional" activities, such as } \\
\text { nonspecific information search, may take place to prepare for } \\
\text { future decisions. In theory, almost all behavior is potentially rel- } \\
\text { evant to present and future decisions, including the avoidance } \\
\text { of defining a particular situation as requiring a decision or } \\
\text { deliberate avoidance of decisions. }\end{array}$ \\
\hline \multicolumn{2}{|r|}{ (2) } \\
\hline Formulation & $\begin{array}{l}\text { The decision situation is explored and classified to include some } \\
\text { understanding of relevant objectives and values. This stage } \\
\text { assumes that people try to achieve preferred outcomes, objec- } \\
\text { tives, or goals, even though they may be unsure, in error, or } \\
\text { unable to express their concepts of value (e.g., time minimiza- } \\
\text { tion, avoidance of high-pressure situations). }\end{array}$ \\
\hline \multicolumn{2}{|r|}{$x_{1}$} \\
\hline $\begin{array}{l}\text { Information } \\
\text { search }\end{array}$ & $\begin{array}{l}\text { This stage involves the identification of attributes or properties } \\
\text { of the alternatives under consideration. Situations in which the } \\
\text { alternatives have known outcomes are considered decisions } \\
\text { under certainty or "riskless choices"; alternatives with } \\
\text { unknown outcomes are considered decisions under uncertainty } \\
\text { or "risky choices." }\end{array}$ \\
\hline \multicolumn{2}{|r|}{ 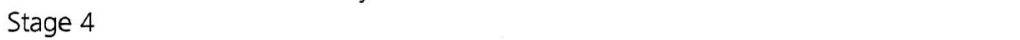 } \\
\hline Feedback & $\begin{array}{l}\text { After decisions have been acted upon, the decision maker may } \\
\text { receive information about the outcomes of the action that per- } \\
\text { mits learning and subsequent changes in substantive knowledge } \\
\text { and decision rules. Feedback is also provided when decisions are } \\
\text { justified to others, such as coworkers or supervisors. }\end{array}$ \\
\hline
\end{tabular}

STUDY QUESTIONS To what extent do the following factors (such
as income level, education level, English-
speaking ability, etc.) help Cecilia in her situa-
tion? To what extent are the following
factors problematic?

After identifying Cecilia's most important short-term and long-term goals, list the three steps Cecilia could take to meet each goal. Specify other individuals and/or organizations you would involve in helping Cecilia achieve these goals.

How important would it be for you to gather the following information (such as family support network, income level, work skills, etc.) about Cecilia as you evaluate her situation? Where would you locate additional information?

Please list the factors you would consider in evaluating Cecilia's progress toward her short-term and long-term goals.
2002). A major advantage is the efficiency of soliciting input from a large number of respondents who can address the same case decision situation without the significant resource outlays, including the time associated with human subjects protections, that are required to investigate real-life decision situations in agency settings. On the other hand, a disadvantage relates to decisions that are lifted from everyday practice where there is no guarantee that the analysis of the case vignette will yield realistic decisions. The hypothetical case using multiple decision cues may be significantly different from actual decision situations. It is possible, nonetheless, to create a sense of realism by identifying critical attributes of typical decision making situations through extensive consultation with experienced practitioners (Carroll \& Johnson, 1990). The focus of the hypothetical case vignette used in this study, which was developed by the participating county agency directors, includes the story of Cecilia, who is an unmarried Latina mother of limited English-speaking ability residing in a neighborhood characterized by high crime and a limited number of employment opportunities (presented in the format of a standardized intake record; see the Appendix).

The decisions made by welfare-to-work staff can be seen as dynamic decisions (Kleinmuntz, 1985) in which a series of related decisions and actions inform each other over a period of time. Carroll and Johnson (1990) have developed a comprehensive framework for analyzing stages of decision making that includes (a) recognition, (b) formulation, (c) alternative generation, (d) information search, (e) judgment or choice, (f) action, and (g) feedback. This framework is built upon a set of discrete stages that are laid out in a linear fashion, though decision makers often use nonlinear approaches where they repeat and backtrack in complex ways.

Using Carroll and Johnson's framework, we developed questions that related to four of the seven stages of decision making: (a) problem recognition, (b) formulation, (c) information search, and (d) feedback (see Table 1). The three stages that relate to alternative generation, judgment, and action were not utilized because they involve complicated and time-intensive tasks of assessing hypothetical actions and cognitive processes. In addition, the hypothetical nature of the case vignette did not allow for an evaluation of specific actions that the respondents might have taken.

\section{Sample}

Thirteen counties participate in the Bay Area Social Services Consortium (BASSC), which is a policy, research, and training partnership between California counties, universities, and foundations. The counties provide social services to the 10 counties that comprise the Bay Area economic region, 2 Central Coast counties, and 1 county 
located in the San Joaquin Valley (as defined by the California Economic Strategy Panel, 2004). The BASSC research agenda is developed in close collaboration with agency administrators and focuses on multicounty studies. Eleven of the BASSC agencies had expressed interest in pursuing a study that focused on the experiences of CalWORKS participants and staff in the context of welfare reform. These 11 agencies, which provide welfare-to-work services to approximately $12 \%$ of California's welfare-towork caseload in the 10-county Bay Area economic region and in 1 Central Coast county (California Department of Social Services, 2004), participated in this study in the spring of 2003 (Austin et al., 2003).

All CalWORKs staff, specialists, and supervisors in the 11 counties were invited by e-mail to participate in the study. Staff included those workers with job titles related to eligibility determination, employment counseling, and case management. The responsibilities of CalWORKs specialists included a wide variety of job functions ranging from intensive work with CalWORKs participants (e.g., vocational assessors, social service program assistants, and social workers) to program analysis and staff development. Supervisors provided support and direction to CalWORKs staff and specialists and in many cases held line staff responsibilities, particularly in the smaller counties. Of the 917 individuals contacted, 161 responded to the decision making questions that related to the case vignette. Fiftytwo of the 161 responses were considered complete in that they included short- and long-term goals, steps to complete the goals, and factors related to evaluation. The remaining 109 cases, which were considered incomplete, were excluded from this analysis.

\section{Data Analysis}

StatPac (Wolnick, 1998) and SPSS (SPSS, Inc., 2003) were used to compile descriptive statistics for Likert-type and fixed-response categories. Atlas.ti (Muhr, 1998) was used to facilitate the qualitative analysis of open-ended responses. To test interrater reliability for the thematic coding of open-ended responses, a random sample of 10 cases $(20 \%)$ was coded by research staff familiar with the project but unfamiliar with the data. The results were compared among research staff and found to be consistent for $95 \%$ of all decisions. The differences that emerged in $5 \%$ of decisions were resolved after review and discussion.

\section{Study Limitations}

The decision making questions were part of a larger survey that was administered using a Web-based format. This format was chosen over a paper survey for the following reasons: (a) faster response time, (b) reduced costs associated with survey management, (c) the elimination of data entry requirements, and (d) the opportunity for interactive error checking. However, in addition to the typical sources of error associated with surveys (e.g., sampling, coverage, nonresponse, and measurement) some of the limitations associated with this study included technical issues (Dillman, 2000). Web-based surveys differ from penciland-paper surveys in that they require Web manipulation skills that will vary with the computer experience of the respondent and can lead to error or nonresponse (Redline \& Dillman, 1999). Depending upon the survey design, respondents may have less control of the survey while scrolling on-screen. In addition, surveys may appear differently depending on the Internet browser used, as well as the size and quality of the user's computer screen. As a result, respondents may view the same question differently and receive different visual stimuli.

In this survey, the approximate 1-hour response time needed for the entire survey may have contributed to respondent fatigue, leading to drop-out, particularly because the case vignette was located in the second half of the survey. Other technical difficulties experienced by respondents included problems related to logging onto the Web site and/or timing out that blocked efforts to complete the survey. It is possible that sensitive questions in other parts of the survey concerning job satisfaction as well as staff attitudes about the agency and CalWORKs participants may have produced a response bias based on concerns about revealing their personal views, despite the guaranteed confidentiality of responses.

Given these limitations, few predictive or prescriptive conclusions can be drawn given the small sample size and the exploratory nature of the study. However, several themes make important contributions to our understanding of welfare reform implementation and to the development of implications for policy, practice, and future research.

\section{Findings}

\section{Respondent Characteristics}

Of the 52 respondents, the majority were female $(80 \%)$ frontline staff $(60 \%)$ between the ages of 36 and 55 years (75\%). Of the $86 \%$ that identified their race or ethnicity, approximately two-fifths were White $(42 \%)$, followed by Asian American (14\%), African American (10\%), mixed ethnicity (12\%), Latino/a (4\%), and other race/ethnicity $(4 \%)$. Over one-third of respondents reported their highest education as the bachelor's degree (37\%) followed by some college $(23 \%)$, master's degree (17\%), associate's degree (15\%), high school diploma (4\%), and $\mathrm{PhD}(2 \%)$. Sixty-five percent of the respondents reported that they had prior experience as eligibility workers and most had 10 or fewer years of public assistance experience (62\%). Onequarter of respondents reported that they had prior experience as welfare recipients (25\%).

The 8 specialists that responded to the survey (15\%) were from two counties and, with the exception of 1 program support analyst, provided intensive services directly to clients. Although these specialists tended to have higher 
education levels when compared to staff and supervisors ( $80 \%$ held master's degrees), few differences were observed in terms of their demographics or their responses. Therefore, specialists were grouped together with staff and supervisors for most analyses.

When compared with staff as a group, the 13 supervisors (25\%) tended to be slightly older and to have obtained higher levels of education. Supervisors also tended to have slightly more experience in public assistance and to have spent more time in their current positions when compared to staff. For example, years of public assistance experience for most supervisors ranged from 6 to 20 years (77\%), whereas the majority of staff had worked in public assistance from 1 to 15 years (82\%). In terms of race and ethnicity, few differences were observed with the exception of Latino/as, all of whom were supervisors $(n=2)$, and Asian Americans, all of whom were staff $(n=7)$. However, given the few differences that were observed between supervisors and staff in terms of their former experiences as eligibility workers or welfare recipients, their caseload sizes, and their responses, the information provided was analyzed in the aggregate for most of the analyses presented.

\section{Recognition Decisions}

The respondents were asked to rate 24 individual, family, community, and employment-specific factors that either helped or hindered Cecilia. As noted in Table 2, respondents considered a number of personal factors to be helpful, including Cecilia's educational interests, Spanishspeaking ability, and motivation level. Other helpful factors included her use of the CalWORKs FastPass for public transportation to her nearby job, her stable housing situation, and her family support in caring for her children. Major personal factors that were considered problematic to respondents included her 10th grade educational level, her mental health status (based on her self-report of a "heavy heart" and her difficulty in getting out of bed), and her lack of health care coverage. Problematic employment related factors included her employer's lack of job flexibility and the limited number of employment opportunities in her neighborhood, which was described as crime-ridden and violent (see Appendix).

There was little consensus among respondents about the adequacy of her income level, the nature of her work history and skills, and her ability to speak English. Similarly, the quality of her job and child care arrangement were seen as both helpful and problematic. This lack of consensus suggests that respondents were focusing on different factors as they attempted to create a balanced assessment of Cecilia's situation by recognizing the positive and negative factors present in the case.

\section{Formulation Decisions}

When asked about the most important long-term goal for Cecilia (i.e., achievable after 2 years), $62 \%$ identified employment or self-sufficiency and 38\% focused on education and training, employment assessments, and job satisfaction. Respondents were also asked to specify the most important short-term goal (i.e., achievable within 1 to 2 years) and the related objectives. In the majority of cases, the short-term goals focused on addressing child care and child safety issues (58\%). One-quarter of the respondents mentioned other short-term goals related to education and training (25\%) including English-language classes, completion of the high school diploma or GED, and computer classes and/or clerical or management training. Other short-term goals included mental health and/or domestic violence assessment/treatment (2\%) and vocational assessment (2\%). Two respondents focused strictly on the acquisition or maintenance of employment $(4 \%)$ as the short-term goal, whereas a similarly small number of respondents (6\%) indicated that the highest priority should be to physically move the family to a safer neighborhood.

Most respondents identified a variety of activities to help Cecilia achieve her goals. For example, the array of activities mentioned to achieve the most frequently mentioned short-term goal, the identification of an alternative child care arrangement, included (a) encouraging the participant to talk to friends about their experiences in using various child care providers and using a list of available child care resources in the neighborhood, (b) setting a timeline for referring the participant to a workshop on how to interview providers, and (c) enrolling the participant in parenting

TABLE 2. Recognition of Helpful and Problematic Factors $(N=52)$

\begin{tabular}{lcc}
\hline FACTOR & HELPFUL & PROBLEMATIC \\
\cline { 2 - 3 } & & \\
& & \\
\hline & & \\
& & \\
$\quad$ Sechilia's interest in earning a high & $98 \%$ & $10 \%$ \\
Cecilia's interest in learning new skills & $96 \%$ & $12 \%$ \\
Cecilia's mental health & $31 \%$ & $81 \%$ \\
Cecilia's motivation & $89 \%$ & $37 \%$ \\
Cecilia's parenting ability & $77 \%$ & $38 \%$ \\
Child care arrangement with family & $90 \%$ & $42 \%$ \\
Child care arrangement with neighbor & $81 \%$ & $94 \%$ \\
Difficulties facing Cecilia & $15 \%$ & $96 \%$ \\
Education level & $46 \%$ & $100 \%$ \\
Employment opportunities in the community & $33 \%$ & $94 \%$ \\
English-speaking ability & $88 \%$ & $63 \%$ \\
Flexibility of job & $15 \%$ & $94 \%$ \\
Health care coverage & $13 \%$ & $77 \%$ \\
Housing situation & $94 \%$ & $35 \%$ \\
Income level & $84 \%$ & $98 \%$ \\
Level of community support & $29 \%$ & $83 \%$ \\
Level of family support & $92 \%$ & $48 \%$ \\
Location of job & $75 \%$ & $42 \%$ \\
Marital status & $6 \%$ & $31 \%$ \\
Quality of job & $69 \%$ & $89 \%$ \\
Spanish-speaking ability & $98 \%$ & $8 \%$ \\
Transportation & $92 \%$ & $31 \%$ \\
Work history & $94 \%$ & $76 \%$ \\
Work skills & $92 \%$ & $94 \%$ \\
\hline & & \\
\hline
\end{tabular}


skills classes. Other respondents focused on the practical dimensions of child care, such as finding a child care provider along the bus line and establishing a way to pay for care. Some respondents felt the child care situation presented serious safety concerns that should be addressed through a referral to community resources such as child protective services, mental health services, domestic violence services, or other welfare-to-work services.

Although respondents were not asked directly about how they would involve Cecilia in service planning, she was mentioned specifically in case planning or decision making by approximately one-third of respondents (31\%). Twenty-two percent of the respondents that identified employment or self-sufficiency as the long-term goal mentioned the need for her involvement in decision making, whereas $45 \%$ of respondents that identified other longterm goals mentioned her involvement.

Respondents were also asked to identify individuals or agencies that could assist Cecilia in achieving the goals identified by the respondent. Given up to seven resources to select from (her employer, family members, friends or neighbors, community-based organizations, other county agencies, their supervisor, and their coworkers), respondents identified as few as zero and as many as seven resources as relevant to achieving short- and long-term goals. Respondents selected an average of three entities to achieve the short-term goal: namely community-based organizations $(83 \%)$, family members $(62 \%)$, and other county agencies $(60 \%)$. To reach the long-term goal, an average of four individuals or organizations were selected, suggesting that goal achievement requires more time and effort as well as more outside support. Community-based organizations $(87 \%)$, other county agencies $(75 \%)$, and family members (56\%) were again most frequently selected to assist the participant in attaining her long-term goals.

\section{Information Search Decisions}

In the context of an information search, respondents were asked to identify the types of information that they would consider in assessing Cecilia's situation and to indicate their primary sources for information. When asked how important it would be for them to consider additional types of information related to Cecilia, her family, her neighborhood, her community, and her current employment, most respondents suggested that every factor was "very important" to consider. More than 90\% of respondents prioritized as "very important" her mental health status (94\%), communication skills (92\%), and interests in obtaining education (92\%) and learning new skills (92\%). Items considered "very important" by roughly two-thirds or fewer of the respondents included items available from the case vignette, including her income level (60\%), health care coverage (59\%), and transportation arrangement $(65 \%)$. Other items considered a high priority included her children's development (67\%), her parenting ability
$(63 \%)$, her level of community support (62\%), and neighborhood factors (58\%).

When asked to select the three most important sources of the information from a list of seven possible sources, respondents listed Cecilia as the most important source $(85 \%)$, followed by the agency database $(39 \%)$ and community-based organizations (31\%). In general, supervisors were the least frequently mentioned sources for information to evaluate Cecilia's situation.

\section{Evaluating Progress}

Finally, to gain insight into the nature of specific feedback decisions, respondents were asked to describe the factors that they would use to evaluate Cecilia's progress toward the short- and long-term goals that they specified. As in Stage 2 goal formulation decisions, a great deal of variability was displayed in the approaches and methods proposed by respondents to evaluate Cecilia's progress. In the majority of cases, the focus of evaluation was her progress toward the long-term goals (63\%); the other respondents emphasized both short- and long-term goals (35\%). In some cases, respondents identified goals that had not been previously mentioned. For example, in an evaluation of whether Cecilia had achieved her goal of enrolling in an adult education program, one respondent suggested that she would assess Cecilia's mental health and stress level as well as her child care situation.

In terms of evaluation methods, respondents frequently mentioned subjective assessments of Cecilia's work motivation, confidence in herself, and her satisfaction with welfare-to-work services. Achievement-oriented indicators for use in evaluation included school attendance and grades, pay increases, and graduation certifications. Respondents also described specific activities they might undertake to obtain the information needed for evaluation, such as gathering information from and consulting with others (e.g., social workers and community-based organizations), interpreting clinical or educational assessments, identifying barriers, and the regular monitoring of progress.

\section{Discussion}

The findings from this exploratory study of case-based decision making suggest that staff members have a substantial influence on how welfare-to-work participants access services, how services are provided, and how success is defined and measured. Whereas previous research has suggested that welfare staff have not always emphasized the importance of developing employment-related goals with participants (Meyers et al., 2001), the majority of respondents in this study formulated goals in agreement with TANF policy goals (62\%). Although a few of the goals and objectives cited by respondents focused exclusively on short-term labor force attachment as a way of moving the participant from welfare to work (4\%), the vast majority of 
goals and objectives reflected an emphasis on developing the CalWORKs participant's skills and abilities as the means for achieving self-sufficiency $(96 \%)$. This finding is consistent with earlier studies of frontline staff under the JOBS program (Hagen et al., 1993; Hagen \& Wang, 1993; Hagen \& Lurie, 1995a; Hagen \& Lurie, 1995b).

The findings from this study suggest that staff discretion may have important implications for both program participants and service outcomes. Though most respondents formulated goals in agreement with the WorkFirst mandate, what is less clear is why $38 \%$ of our respondents formulated long-term goals (i.e., goals to be achieved after 2 years) that related to alternative child care, education and training, and employment assessments. Considering that Cecilia's remaining CalWORKs benefit would expire in 2 years and 3 months, a few explanations are possible. In complex situations such as Cecilia's, 2 or more years may not be seen as a reasonable time frame for gaining better employment while she is engaged in other welfare-to-work activities (e.g., acquiring a second language, earning a high school diploma, or taking computer courses). In fact, some respondents noted that they would exercise even greater discretion by encouraging Cecilia to attend a 4 -year college after finishing her GED if it were not for the CalWORKs time limits. On the other hand, the lack of a clearly stated employment goal might also suggest that the respondents considered Cecilia's current employment situation satisfactory. Although it is possible that the respondents assumed that better employment or an increased number of work hours were implicit programmatic goals that did not need to be explicitly stated, further research is necessary to determine if this was the case.

Another issue relates to the inconsistencies that we identified between the decision stages of problem recognition, information search, and goal formulation during the analysis. In the problem recognition stage, the majority of respondents prioritized issues such as Cecilia's mental health, her health care coverage, job flexibility, employment opportunities in the community, and her lack of community support. Yet very few of the goals that were formulated related to these problems. In contrast, the majority of respondents gave top priority to the formulation of child care and child safety goals (58\%), an issue that received less attention in the problem recognition stage. Similarly, relatively fewer respondents identified Cecilia's parenting ability or her children's development as a priority for assessment in the information search stage. Further research is needed to identify how workers obtain and evaluate information (particularly the duration of benefits) and how this process guides case planning. Although we found no relationship between caseload size and the decisions at hand, clearly this is a factor that influences staff's day-to-day decision making and should also be considered in future research.

The finding that $31 \%$ of the respondents explicitly men- tioned involving Cecilia in case planning or decision making should be treated cautiously because respondents were not asked directly about the importance of involving her in these activities. Additional research will be needed to determine how and to what extent staff involve participants and how they conceptualize their roles. The limited involvement of Cecilia in case planning may reflect an ambiguity about the roles of eligibility determination and case management. For example, Beckerman and Fontana (2000) found that some case managers identified their role as a "service broker," linking participants to services, whereas others identified their role as a "facilitator" with responsibilities to motivate participants to follow through on their case plans. Since the organizational culture of welfare programs has changed from eligibility determination to employment-focused case management services, new staff roles are likely needed to emphasize participant empowerment in decision making as well as the community outreach aspects of service brokering. Given that the majority of frontline workers are former eligibility workers who may not have received training in case management, more training on client assessment and evaluation skills is of priority. Many states have not invested in training or information resources due to caps placed on administrative costs in the TANF legislation (Lurie, 2002). Clearly this is an area in need of attention given the preparation that frontline workers need in order to perform these complex tasks that are qualitatively different from eligibility determination.

In general, future research is needed to identify the specific factors that workers utilize when formulating goals and objectives; how they select, weigh, and prioritize factors that appear in a case; and how these factors change over time. In the meantime, standardized guidelines represent a promising tool for identifying important data elements, specifying optimal service strategies, and defining measures of outcome. Past research has also demonstrated the influence of the organizational environment on worker decision making (see Weissert, 1994). Factors such as professional and policy orientations; managerial styles, attitudes, and expectations; the degree of discretion granted to staff; and employees' own values and preferences represent important factors to examine at the local level in future research.

In this study, community-based organizations, family members, and other county agencies were frequently identified as important resources for achieving self-sufficiency. The involvement of an average of four individuals or organizations to support the participant in goal achievement reflects the shared responsibility for welfare-to-work programs. Additional research is also needed to identify how community resources are mobilized to support goal achievement, particularly given the low priority given to community and neighborhood development activities that may be outside the skills of case managers. Given the 
frequency with which staff prioritized the involvement of community-based organizations and other county agencies, it is important to examine the ways in which interagency collaboration is facilitated and enhanced at the neighborhood level. Such an examination should include the community's philosophy about the role of government, its responsibility to those in need, and the networks of resources that are made available to participants (Henly \& Danziger, 1996).

Finally, these findings raise questions about the lack of sufficient attention to the role that child well-being plays in day-to-day frontline decisions. These findings suggest that the majority of respondents gave top priority to child care and child safety goals (58\%). Yet many others ( $42 \%)$ gave higher priority to work, education, and skill development despite Cecilia's poor child care situation. The implications of high levels of discretion become important when considering such disparate child well-being outcomes, ranging from child protective services intervention due to abuse or neglect at one end to no intervention on the other. Given that welfare-to-work staff have been given the responsibility and discretion for implementing new policies that impact the life experiences of society's most vulnerable children and families, additional knowledge is needed to increase our understanding of the decision making processes that guide TANF service delivery systems in order to identify ways to improve upon them.

\section{References}

Austin, M. J., Johnson, M. A., DeMarco, A., Ketch, V., \& Chow, J. (2003). Delivering welfare-to-work services in county social service organizations: An exploratory study of staff perspectives. Berkeley, CA: Bay Area Social Services Consortium, University of California.

Beckerman, A., \& Fontana, L. (2001). The transition from AFDC to PRWORA in Florida: Perceptions of the role of case manager in welfare reform. Journal of Sociology and Social Welfare 28(3), 29-47.

Brodkin, E. Z. (2000). Investigating policy's practical meaning: Street-level research on welfare policy (Working Paper 162). Chicago: Joint Center for Poverty Research, Northwestern University.

California Department of Social Services. (2004). CalWORKs program percent of population receiving CalWORKs: January 2004. Retrieved November 11, 2004, from

http://www.dss.cahwnet.gov/research/res/pdf/caltrends/poprec/CW PopRecJan04Map.pdf

California Economic Strategy Panel. (2004). California Economic Regions. Retrieved November 11, 2004, from http://www.labor.ca.gov/panel/ESP_Regions_brochure-Mar_04.pdf

Carroll, J. S., \& Johnson, E. J. (1990). Decision research: A field guide. Thousand Oaks, CA: Sage.

Carnochan S., \& Austin M. J. (2002). Implementing welfare reform and guiding organizational change. Administration in Social Work, 26, $61-77$

Cherlin, A. J., Bogen, K., Quane, J. M., \& Burton, L. (2002). Operating within the rules: Welfare recipients' experiences with sanctions and case closings. Social Service Review, 76, 387-405.

Dillman, D. (2000). Mail and Internet surveys: The tailored design methods (2nd ed.). New York: Wiley.

Doolittle, F., Gooden, S., \& Robles, A. (2003). Community service jobs in Wisconsin Works: The Milwaukee County experience. New York: Manpower Development Research Corporation.
Gais, T. L., Nathan, R. P., Lurie, I., \& Kaplan, T. (2001). Implementation of the Personal Responsibility Act of 1996. In R. M. Blank \& R. Haskins (Eds.), The New World of Welfare. Washington, DC: Brookings Institution Press.

Hagen, J. L., \& Lurie, I. (1995a). Implementing JOBS: A view from the front line. Families in Society, 76, 230-238.

Hagen, J. L., \& Lurie, I. (1995b). Implementing JOBS: From the rose garden to reality. Social Work, 40, 523-532.

Hagen, J. L., Lurie, I., \& Wang, L. (1993). Implementing JOBS: The perspective of front-line workers. New York: The Nelson A. Rockefeller Institute of Government.

Hagen, J. L., \& Owens-Manley, J. (2002). Issues in implementing TANF in New York: The perspective of frontline workers. Social Work, 47 , 171-182.

Hagen, J. L., \& Wang, L. (1993). Roles and functions of public welfare workers. Administration in Social Work, 17(2), 81-103.

Hagen, J. L., \& Wang, L. (1994). Implementing JOBS: The functions of frontline workers. Social Service Review, 68, 369-385.

Hasenfeld, Y., Ghose, T., \& Larson, K. (2004). The logic of sanctioning welfare recipients: An empirical assessment. Social Service Review, 78, 304-320.

Henly, J., R., \& Danziger, S. K. (1996). Confronting welfare stereotypes: Characteristics of general assistance recipients and postassistance employment. Social Work, 20, 217-227.

Holcomb, P. A., \& Martinson, K. (2002). Putting policy into practice: Five years of welfare reform. In A. Weil \& K. Finegold (Eds.), Welfare reform: The next act. Washington, DC: Urban Institute Press.

Keiser, L. R., Mueser, P. R., \& Choi, S. (2004). Race, bureaucratic discretion, and the implementation of welfare reform. American Journal of Political Science, 48, 314-327.

Kleinmuntz, D. N. (1985). Cognitive heuristics and feedback in a dynamic decision environment. Management Science, 31, 680-702.

Lipsky, M. (1980). Street-level bureaucracy: Dilemmas of the individual in public services. New York: Russell Sage Foundation.

Lurie, I. (2002). Changing welfare offices. In I. V. Sawhill, R. K. Weaver, R. Haskins, \& A. Kane (Eds.), Welfare reform and beyond: The future of the safety net. Washington, DC: Brookings Institution.

Meyers, M., Riccucci, N., \& Lurie, I. (2001). Achieving goal congruence in complex environments: The case of welfare reform. Journal of Public Administration Research and Theory, 11, 165.

Montgomery, L., Kaye, K., Geen, R., \& Martinson, K. (2002). Recent changes in California welfare and work, child care, and child welfare systems. (State Update No. 11). Washington, DC: The Urban Institute.

Morgen, S. (2001). The agency of welfare workers: Negotiating devolution, privatization, and the meaning of self-sufficiency. American Anthropologist, 103, 747-761.

Muhr, T. (1998). Atlas.ti for Windows. Berlin, Germany: Scientific Software Development.

Redline, C., Dillman, D., Smiley, R., Carley-Baxter, L., \& Jackson, A. (1999). Making visible the invisible: An experiment with skip pattern instructions on paper questionnaires. Available: http://survey.sesrc.wsu.edu/dillman/papers/Making\%20Visible $\% 20$ the\%20Invisible.pdf

Riccucci, N. M. (2002). Implementing welfare reform in Michigan: The role of street-level bureaucrats. International Journal of Public Administration, 25, 901-921.

Sandfort, J. (1999). The structural impediments to human service collaboration: Examining welfare reform at the front lines. Social Service Review. 73, 314-339.

SPSS, Inc. (2003). SPSS Graduate Pack 11.5 for Windows. Chicago: Author.

Weissert, C. S. (1994). Beyond the organization: The influence of community and personal values on street-level bureaucrats' responsiveness. Journal of Public Administration Research and Theory, 4, 225-254.

Wolnick, D. (1998). StatPac for Windows. Minneapolis, MN: StatPac, Inc. 
APPENDIX

Case Vignette in the CalWORKs Intake Record Format:

Participant Name: Cecilia

Marital Status: Single

Age: 24 years

Children: Jamie, Age 3; Maria, Age 7

Involvement of Other Parent/Caretaker(s): Family lives nearby and helps with child care from time to time. Cecilia has no contact with the father of her children. The father does not pay child support. An exempt provider ( $a$ friend) in the same apartment complex cares for the children when Cecilia is at work. CalWORKs pays for the care of the children.

Education: Cecilia has completed 10th grade. She would like to earn her high school diploma.

Employment Status: Cecilia works part-time from 1:00 p.m. to 6:00 p.m. daily. She earns $\$ 8 / \mathrm{hr}$ with no health benefits.

Work History: Cecilia began work when her youngest child was 12 months old. She has been working in the same job for 2 years at a neighborhood grocery store.

Work Skills: Cecilia has had mostly manual work experience. She has learned to use the cash register. Occasionally she enters stocking information into the store's computer with her employer's supervision. She has expressed interest in taking a computer course.

Housing Status: Stable

Number of Residents in the Home and Their Relationship to the Participant: Three (participant and two children)

Monthly Rental Rate: $\$ 1,000$

Total Monthly Gross Income: $\$ 1,500$

Transportation: Uses transportation pass.

Type of and Length of Time on Public Assistance: Grant is $\$ 104$, food stamps is $\$ 97$. Cecilia has used 2 years and 9 months of her 5-year CalWORKs lifetime limit.

Additional Information: Many employers have left Cecilia's community due to high crime and violence. Her employer is one of few that have stayed. He says he pays a good wage for a person with limited English-speaking ability and no computer skills. He relies heavily on Cecilia to serve his Spanish-speaking customers. He is not flexible about absences and threatens to let her go whenever she asks for time off, even for just a few hours.

Cecilia's child care arrangement with her neighbor is convenient; however, Cecilia is uncomfortable with the neighbor's boyfriend who sometimes yells at her children. Today she has brought her older child Maria to your office while Cecilia's mother cares for her younger son. Cecilia mentions that her "heart is heavy" and that lately it has been very difficult for her to get out of bed in the morning. As Cecilia and Maria leave the office, you ask about Maria's arm, which is in a sling. Cecilia states that Maria slipped and fell while playing at the child care provider's apartment.
Michelle A. Johnson, MSW, is a doctoral student, School of Social Welfare, University of California, Berkeley. Julian Chun-Chung Chow, $\mathrm{PhD}$, is associate professor, School of Social Welfare, University of California, Berkeley. Virginia Ketch, MSW, is research assistant, School of Social Welfare, University of California, Berkeley. Michael J. Austin, $\mathrm{PhD}$, is professor, School of Social Welfare, University of California, Berkeley. Correspondence regarding this article may be addressed to the last author at mjaustin@berkeley.edu or School of Social Welfare, University of California, Berkeley, 120 Haviland Hall, Berkeley, CA 94720.

Authors' note. This paper was based on the Welfare to Work Research Project funded by the Bay Area Social Services Consortium, the Zellerbach Family Foundation, and the VanLobenSels/RembeRock Foundation in northern California.

Manuscript received: June 25, 2004

Revised: November 18, 2004

Accepted: December 8, 2004 